\title{
Finding handaxe homogeneity from the expedient assemblage in Korea
}

- Hyeong Woo Lee

Chonbuk National University, South Korea

\section{ABSTRACT:}

The symmetrical perspective is crucial for understanding human behavior. Paleolithic handaxes are a good candidate for such a quantitative analysis. To avoid individual and arbitrary judgments, a more objective method is required. Recently, plausible means of metrical measurements have been introduced. One of them, the 'flip test', is used to quantify various aspects of Korean Paleolithic handaxes.

Normally, the handaxes in Korea are from the assemblage which dominated by expediently made core and flake tools. Unlike typical Acheulean handaxes, the handaxes from Korea do not show strong standardization tendency. The primary question is whether the strong pattern of variation in a continuous single direction or not (e.g. an increasing degree of symmetry with decreasing site age would indicate increased cultural and technological complexity). However, the results do not fully demonstrate a significant relationship. In other words, symmetrical homogeneity has been observed.

Keywords: South Korea, handaxes, symmetry, flip test

1. Introduction: terms of handaxe and symmetry

Acheulean handaxes have very pervasive features in comparison with other types of tool from the Paleolithic period. In terms of chronology, the manufacture of this tool type can be traced back to around 1.5-1.7 mya (Gibbon et al. 2009, Klein 2009, Ambrose 2001). The type was made and used by various hominids-Homo ergaster, Homo erectus, Homo heidelbergensis and more. When considering up-dated archaeological results, the hominids who made them can be extended to Homo sapiens. Based on these multiple human agents, ancestor-descendant model mediated strong cultural learning and transmission has been questioned. Nevertheless, pervasive shape consistency cannot be rejected.

In fact, chopping tools and simple flakes and flake tools might be the longest-surviving artifacts.
However, these tools were not made according to a strong predetermined plan, so they cannot be treated as the same line of lithic manufacture sequence as handaxes. Handaxes were purposely designed prior to knapping, using a design concept that remained almost unchanged for a long period.

Homogeneous features in terms of space are also examined. Acheulean handaxes have been found everywhere in the Old World, with a few regional exceptions, from Africa to East Asia. The handaxe population density differs regionally. Acheulean handaxes are rare in Asia (Norton and Bae 2009). In Korea, about 30 years of Paleolithic research has been conducted, and more than 150 Paleolithic sites have been studied (Bae 2010). Nevertheless, only a few hundred sites have been excavated, which does not compare to some prolific single sites in Africa or Europe. However, the 
presence of Acheulean handaxes in Korea is undeniable.

The initial discovery of handaxes (Acheuleanlike handaxes) in Korea was made in Chongokni during the late 1970s (Kim and Chung 1978, RICP 1983). The study of Paleolithic handaxes in Korea does not have a long history, but the morphological similarity with those from Africa and Europe was so astonishing that inferences can be made from research in other regions. The chronology of handaxes is quite different from that in Europe and Africa. The Acheulean handaxes represent the early period artifacts, but the precise age of the beginning of handaxe production in Korea is unclear. The oldest site might be Chongokni, which is 300500,000 years old, although more accurate dating results are required.

From a typological point of view, the similarities of Acheulean handaxes with those from Africa and Europe are well known. This similarity is verified by the tripartite shape diagrams generated by Roe (Roe 1968, 1981). A comparative study conducted with major Korean handaxe groups, mainly from Chongokni and major British and African (especially, Olduvai Gorge) handaxe groups, suggests that the shape tendency (particularly pointedness and broadness) is seemingly identical (see Figure 1 Lee 2006). However, doubt remains. Like other handaxes from Asian sites (Corvinus 2004), whether the Korean examples are proper Acheulean handaxes is debated.

The question of the function of Acheulean handaxes also needs to be resolved. As explained, handaxes in general tend to be consistent across space and time. Korean handaxes do not deviate from this. Recent micro-wear and experimental studies have suggested that handaxes made of flint are used for butchering (Mitchell 1996). However, the function of handaxes might not have remained consistent due to changes in the availability of raw materials across space and time. The idea of functional consistency is unlikely to be applicable to Korean handaxes. Most Korean handaxes were knapped with relatively poor-quality rock such as quartzite (Seong 2004), so the working edges are not always finely prepared. Therefore, whether such handaxes have the same function as those made of fine-quality rock is unclear.

An alternative explanation for the temporal and spatial consistency of Acheulean handaxes is provided by the socio-cultural complexity theory. Socio-cultural complexity due to different climatic conditions suggests another dimensional interpretation of handaxes. In comparison with poorly made tools, such as chopping tools, the handaxe industry operated in a different climate in the presence of various levels of social complexity (Roebroeks et al. 1992). The different climatic phases resulted in production of different tool-kits: a cold-adapted society tends to produce more complex artifacts such as handaxes, while a warmadapted society produced poor-quality artifacts, such as chopping tools. Secure chronometric data are required to assess this possibility. If the data sets are inadequately calculated, the proposed patterned variation may not be productive.

Handaxe research started in terms of type, time and space, and then extended to function and society. All of this research is largely based on cultural adaptation mechanisms. Culturally transmitted tendencies are central to an understanding of human behavior. Nevertheless, some questions remain. Firstly, handaxes from Africa and East Asia are separated by a gap of over 1 million years. This gap is too large to be explained by information transmission, tradition diffusion and cultural learning episodes.

The reason suggests a different dimensional explanation. The fundamental questions are why the handaxe shape remained so consistent throughout time and space and why the toolmakers attempted to build the same or a similar tool type throughout time and at all locations. When understanding or

\section{Trang 78}


even reconstructing past human behavior, it is essential to perceive changes such as in artifact types, traditions, lithic complexity and subsistence pattern. Equally, it is also essential to perceive homogeneous characteristic features.

2. Korean Paleolithic handaxes from three geographical contexts

Table 1 and Figure 1 show selected Korean handaxe data from the excavated sites. Compared to the typical Acheulean handaxe sites from west of the Movius Line (ML) (for more information, see Movius 1948, Schick 1994, Norton and Bae 2009, Petraglia and Shipton 2008), the quantity and sites are not large (Norton and Bae 2009). The Korean handaxe is not a dominated type of tool within the assemblage which mostly comprises expediently made tools. Most handaxes are often found with chopping tools and polyhedrons although some handaxes are associated with blades as well.

As seen the Table 1, the handaxes and handaxe occurring sites are not many. The listed examples are confined to excavated materials, surfacecollected handaxes are omitted. To reduce unexpected error, excavated and surface-collected items should be considered as separate entities. Artifacts from stratified deposits should be subjected to various analyses, including comparative chronological studies. Although unexcavated ones are not included, the total number is not sharply increased. In other word, Korean case can be understood as a part of the east of the Movius Line (ML).

Morphologically, not all the handaxes are made complex reduction strategy (see Figure 2). Through the entire Paleolithic period of time, the majority of Korean Paleolithic tool-kits are comprised of expediently made core and flake tools sometimes even during the Late Paleolithic period of time (Lee 2013a). The lithic assemblages occurring handaxes do not always show advanced technological traits.

Table 1. Distribution of handaxes in the three regions

\begin{tabular}{|l|l|c|l|}
\hline Region & Site & N. of tested & H/T horizon \\
\hline \multirow{4}{*}{$\begin{array}{l}\text { Imjin/Hantan } \\
\text { (IHRB) }\end{array}$} & Chongokni & 24 & $\mathrm{M} / \mathrm{M}$ \\
\cline { 2 - 4 } & Jangnamgyo & 9 & $\mathrm{M} / \mathrm{M}$ \\
\cline { 2 - 4 } & Namkaeri & 1 & $\mathrm{~S} / ?$ \\
\cline { 2 - 4 } & Kumpari & 9 & $\mathrm{~S} / \mathrm{M}$ \\
\cline { 2 - 4 } & Jangsanni & 1 & $\mathrm{~S} / \mathrm{S}$ \\
\cline { 2 - 4 } & Kawoli & 1 & $\mathrm{~S} / \mathrm{S}$ \\
\hline \multirow{5}{*}{ East Coast (EC) } & Shimgokni & 1 & $\mathrm{~S} /$ \\
\cline { 2 - 4 } & Wolso & 9 & $\mathrm{M} / \mathrm{M}$ \\
\cline { 2 - 4 } & Pyeongneungdong & 3 & $\mathrm{M} / \mathrm{M}$ \\
\cline { 2 - 4 } & Nobong & 1 & $\mathrm{~S} /$ \\
\hline \multirow{5}{*}{ Geum River Basin (GRB) } & Songduri & 5 & $\mathrm{~S} /$ \\
\cline { 2 - 4 } & Mansuri & 5 & $\mathrm{M} / \mathrm{M}$ \\
\cline { 2 - 4 } & Nosanri & 3 & $\mathrm{M} / \mathrm{M}$ \\
\cline { 2 - 4 } & Seokjangri & 3 & $\mathrm{M} / \mathrm{M}$ \\
\cline { 2 - 4 } & Ssangjungri & $\mathrm{S} / \mathrm{M}$ \\
\hline
\end{tabular}

***Note: all handaxes were excavated, surface-collected handaxes are not included. $N$. of tested: actual numbers of handaxes, total numbers may be larger than that. However, testable cases are not necessarily equal. H/T horizon: $H$ is the number of archaeological horizon(s) containing handaxes and $T$ is the total number of horizon(s) that yield any lithic materials. $M$ (multiple layers), $S$ (single layer). 
Figure 1. The handaxes occurring sites which are mentioned in the text

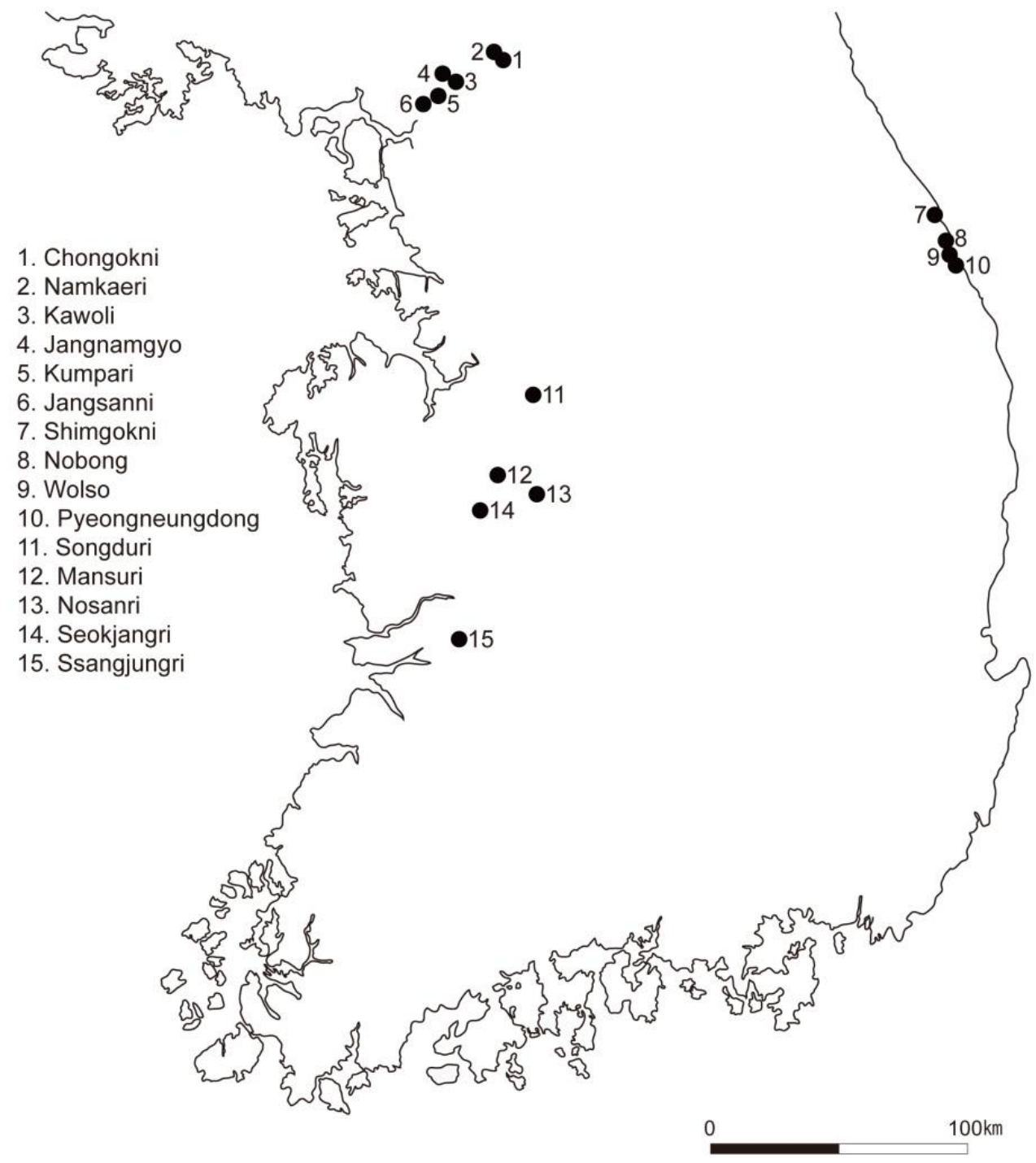

For a regional comparison, handaxes from two basins and one coastal region are tested. These are from the Imjin/Hantan River Basins (IHRB), Geum River Basin (GRB) and the East Coast (EC). These three areas have diverse geological and chronological contexts. Unlike to the initial comparative analysis (Lee 2011), this work tries to accommodate the updated high resolution sites which offer chronometric data. The sites Jangnamgyo, Wolso, Pyeongneungdong and
Ssangjungri are the examples. In additions, finding regional variation which was not properly done has been concerned.

The IHRB sites comprise Chongokni, Jangnamgyo, Namkaeri, Kumpari, Jangsanni, and Chuwoli/Kawoli. The IHRB has a river system. A full explanation of all sites is beyond the scope of this paper purpose, so only a few significant sites are explained. Chongokni has been researched since the 1970s not only because of collection of various

\section{Trang 80}


forms of Acheulean-like handaxes but also the age of the handaxes. The initial proposed date for the site is more than 300 kya (Kim and Chung 1978) based on typological aspects and chronometrical data. The age of the site remains a matter of debate. Some scholars still favor 300 kya (Norton et al. 2006, Bae 1988), while an alternative age has been suggested (Yi 1996).

Although chronological debate has continued for more than 30 years, precise dating has not been achieved. Several methods have been used; e.g., K/Ar Dating, Tephra analysis, Quaternary terrace deposits research, micro-morphology on sediments Loess sequence research etc. The maximum date has been estimated as 350-300,000 BP (Norton et al. 2006), although the gap between the maximum and minimum dates is significant (Bae 2003, 19). However, there is a possibility of younger handaxes, due to possible re-deposition after the post-depositional process or the presence of another (younger) cultural layer (Seong 2006, 9-10). Artifacts from 350-300 kya might not be in situ because they were incorporated within a secondary context. Indeed, the debate has been stimulated by the accumulation of research.

Jangnamgyo is a relatively recently excavated site within the IHRB (see Bae et al. 2011). Cosmogenic isotope analysis was used for chronometric dating (26Ale-10Be isotope analysis), which is a first in Korean Paleolithic research. However, the chronological range cannot be resolved. For example, the layer 'Loc. 1. SL 5. light yellowish brown' is as old as $55.9 \pm 2.4$ kya $\mathrm{BC}$ by OSL dating, while 26Ale-10Be isotope analysis yielded 454,000 $\pm 94,000$ BP (Bae et al. 2011). Although the dates are controversial, the possibility of Middle Pleistocene hominid occupation is still valid. The nine handaxes are listed in Table 1. This number of handaxes cannot be overlooked in the Korean context. Unlike localities in Africa and Europe, which yield a large number of typical Acheulean handaxes, nine is not small.
Nine handaxes have been recovered from Kumpari, similar to Jangnamgyo (Table 1). Kumpari has been reported to the multi-layered site. Bifacially worked core tools have been found in one (in the first deposit beneath the top soil). The postdepositional process is difficult to reconstruct, but it might have formed under fluvial conditions. Nevertheless, the possibility of an Aeolian episode must also considered (NRICP 1999). The first cultural layer from which handaxes were recovered is believed to have been re-deposited by postdepositional processes. Unlike Chongokni and Jangnamgyo, sophisticated chronometric results cannot be expected.

Most Paleolithic artifacts from IHRB sites show affinity with the early lithic tradition. Absence or sparse of artifacts from a later period (e.g. blades, micro-blades or projectile points) suggests the early tool tradition. The suggested chronology also supports a date older than the Late Paleolithic. Although it cannot firmly assure, dominated occupational period time of the sites from IHRB might be the early episode.

Unlike the Imjin/Hantan River Basins (IHRB) and Geum River Basin (GRB), the East Coast (EC) does not have a lengthy drainage system. The EC is located east of the ridge of the Taebaek Mountains, which is the primary mountain ridge on the Korean peninsula and located at its eastern edge (Britannica 2016). Therefore, the EC region is long and narrow and faces a steep ridge to the west and the East Sea to the east. In terms of its geological features, it is hard to move between east and west, but reaching along the coast line which starched north-south is relatively easy. In terms of movement pattern, the EC might be a more isolated and remote region than the IHRB and GRB.

Site Wolso has a vast number of Paleolithic artifacts. More than 2000 artifacts have been recovered from various horizons; 9 handaxes were recovered from several cultural layers in localities A-1, A-2, B and C (YICP 2010). The associated 
lithic materials are normally simple core and flake tools. No elaborate tools, such as blades or micro blades, have been collected, even in the upper layers; therefore, there is no sign of affinity with the Later Paleolithic. A tanged projectile point has been recovered, but has been reported to have been made at a separate location (NRICH 2013). Radiometric dating was performed by accelerator mass spectrometry (AMS) and optically stimulated luminescence (OSL), and the results vary according to method and location. The oldest claimed date offered by OSL is 96,000 $\pm 14,000 \mathrm{BP}$.

At Shimgokni, only one handaxe of possible age 40-50,000 BP was found. The sequence of geological horizons is top soil - gravel-dominated layer - silt-dominated layer. The cultural layer is the lowest one. A tabular form of nodule is used for this handaxe, and there is no heavy retouching or trimming of flaking. The incorporated artifacts are mostly simple core tools and flakes (Yi 2006). A possible implication is that the site was likely to be reworked. In fact, reworking is ongoing and the adjacent gravel-dominated layer could suffer from the colluvial environment. Therefore, the possibility of major movement during formation of the site should be considered.

Nobong also yielded only a single handaxe from the second cultural layer. Most of the incorporated items are simple core tools, such as chopping tools. However, the proposed chronology is younger than the typical Early Paleolithic period. The chronometric data of handaxe-occurring layer is $33,300 \pm 1,700 \quad$ BP $\quad(38,565 \pm 3,570 \quad$ BP with calibration) (Choi et al. 2003). It is therefore considered likely that the handaxe tradition in Korea lasted until the Upper Palaeolithic period as an independent entity from the blade, micro-blade or tanged points tradition. The morphology of the handaxe showed a unique feature. Unlike typical samples, it is made of porphyry and shows a very flat cross-section. In fact, most tools from the site are made of quartzite; tools made of porphyry are rare. A flat handaxe generally indicates heavily retouched and refined knapping. However, it may have been due to an original flat blank shape, which induced the flat form of the final product.

The Geum River Basin (GRB) sites are Seokjangri, Songduri, Mansuri, Nosanri and Ssangjungri. GRB is one of the main drainage systems in the southern part of Korea. Seokjangri is a significant site in terms of archaeological history in Korea (see more Sohn 1967, 1972, 2002). It is the oldest excavated site in South Korea. It was excavated in 1964 and further research was carried out recently. In total, 13 excavation seasons have been conducted. The stratigraphy is complicated, comprising a total of 27 horizons. Of these, 13 horizons are regarded as cultural layers. Researchers tend to sort them into three chronological epochs following the threefold cultural system (the Lower, Middle and Upper Paleolithic) (Sohn 1993). The chronological and typological divisions in the Korean Paleolithic remain unclear, and the merits of the twofold cultural system (the Early Paleolithic and Late Paleolithic) and threefold cultural system have been debated (Lee 2013a). Therefore, the chrono-typo description of lithic tools varies depending on the authors.

The first assemblage Seokjangri is dominated by simple tools produced using expedient lithic technology (NRICH 2013). For example, deposits from which chopping tools and picks are collected are termed chopping tool associated-deposits. The second assemblage comprises handaxes and later assemblages provide various blade and micro-blade tools (NRICH 2013). Occasionally, materials from prior to later assemblages are chronologically and technologically criticized (Seong 2015). Six handaxes are tested in this paper. These are not from the same deposit; two handaxes are from each of chopping tool associated deposits, handaxeassociated deposits and Upper Paleolithic deposits.

\section{Trang 82}


Therefore, the handaxes from Seokjangri might be interpreted as a time-continuum type.

The Mansu-ri site was excavated recently. The handaxes referred to herein came from Localities 2, 3, 12 and 14 (Lee et al. 2010, 2009, IKP 2009). In total, five handaxes not excavated from the same deposit were tested. With one exception, all of the handaxes are reported to belong to Cultural Layer 1 . The stratigraphic correlations across localities are unclear, as is whether these are from genuinely identical deposits. Therefore, not only the locality but also stratified deposits are not perfectly consistent. The radiometric data are also controversial. The chronometric results exhibit marked variation; the oldest result from the lowermost cultural layer is circa 0.5 mya while OSL results generally suggest less than 100 kya.

A handaxe group from the Ssangjungri site represents a non-typical case. The incorporated artifacts are simple core and flake tools, such as chopping tools comprising polyhedrons. Since these are fossil types of the Early Paleolithic, the handaxes are likely Lower Paleolithic handaxes. However, the radiometric data suggest that these belong to the time span of the Late Paleolithic. This is similar to the case of Nobong, which has three different cultural layers among a total of 10 geological layers. Cultural Layer 1 is further divided into Layers 1-1, 1-2, and 1-3. The handaxes are mainly from Cultural Layer 1-3, which dates to $30,218 \pm 148$ B.P. (AMS). However, this is not a calibrated date; the date calibrated using OxCal is $34,831 \pm 245$ B.P. (AMS) (Kim et al. 2012, Lee 2013b). These data demonstrate that the handaxes might survive until the Late Paleolithic. Moreover, handaxes in Korea is not the truly representative as an exclusive cultural marker for earlier episode.
Figure 2. The examples from selected Korean Paleolithic sites, 1: Chongokni, 2: Pyeongneungdong, 3: Pyeongneungdong. 4: Mansuri, 5: Ssangjungri (Bae and W. 1993, ICPH 2009, Choi 2010, Lee et al. 2009, Kim et al. 2012).

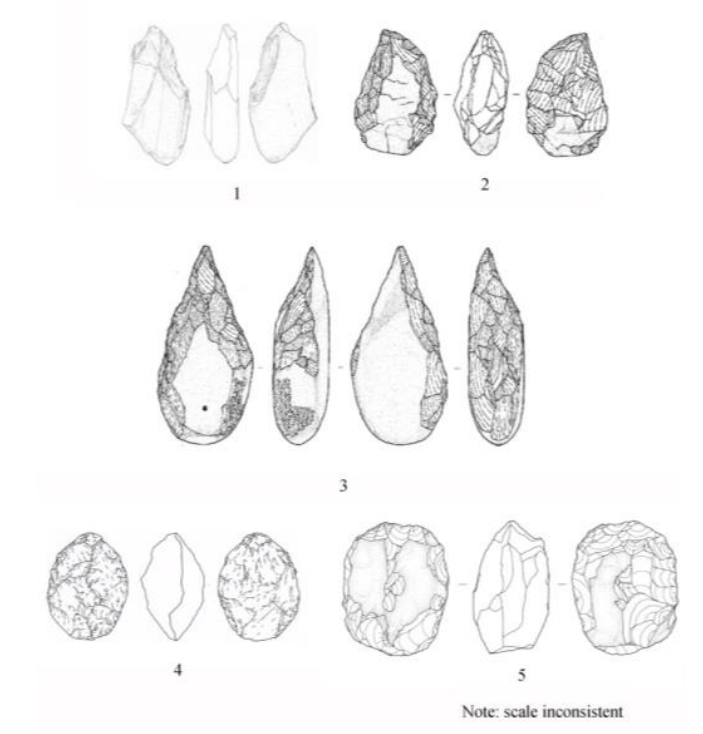

\section{Analysis}

The symmetrical forms of many handaxes are commonly discerned visually. However, determining the degree of difference between two handaxes is difficult. Although researchers have correctly noticed differences, the difficulty in verifying and persuading others necessitates metric and statistical analyses. Pioneer work on this issue was performed by Wynn and Tierson (Wynn and Tierson 1990). Their method is based on 'the polar coordinate measurements'(Wynn and Tierson 1990, 74). Several points are measured on the outline of the handaxe starting from the center, which is the middle of the long axis. Another method called 'continuous symmetry measure' (CSM) is used to evaluate the degree of symmetry in a measurable property (Saragusti et al. 1998). Therefore, the CSM method provides objective symmetry data. And this method has been applied to the actual Paleolithic handaxes (Saragusti and Goren-Inbar 2001). 
Table 2. Description of the asymmetry index and class (from Hardaker and Dunn 2005)

\begin{tabular}{|l|l|l|}
\hline Class & Asymmetry & Level of symmetry and interpretation \\
\hline 1 & $1.0-1.49$ & $\begin{array}{l}\text { Virtually perfect. Suggests an almost mathematical level of precision has been } \\
\text { applied. }\end{array}$ \\
\hline 2 & $1.5-2.99$ & Very high. An exceptionally skilled craftsman - special purpose? \\
\hline 3 & $3.0-3.99$ & High. Skilled work. \\
\hline 4 & $4.0-4.99$ & Moderate. Average work. \\
\hline 5 & $5.0-5.99$ & Low. Look for intractable material, or eccentric shape e.g. on butt. \\
\hline 6 & $6<$ & $\begin{array}{l}\text { Very low. Look for intractable material, serious material defects, eccentric shape } \\
\text { or a modern break. }\end{array}$ \\
\hline
\end{tabular}

Unlike the above two methods, the flip test enables easy and reliable measurement. In the flip test, both sides of the handaxe are measured using computer software (Hardaker and Dunn 2005). As in the previous methods, the outer surface of the handaxes is measured, but the flip test covers the entire outline, rather than merely a few points. In addition, the result is presented as a numerical value to enable comparison. The final advantage is the suggestion of a symmetry class from class 1 to 6 , which indicate superb and poor symmetry, respectively (Table 2).

The symmetrical analysis of the Imjin-Hantan region has been carried by flip test (Kim 2009). Tested artefacts on the paper are including surface material as well. The present author has two questions; first identifying a chronologically valid sample, and second, their comparison with another context. Because the questions differ, the samples are confined to materials obtained from systematic excavations.

In total, 81 handaxes from 15 archaeological sites in three regions were analyzed. For in-depth comparison, the obtained measurement data should be high-resolution (i.e., secure from the effects of contamination and laboratory factors, cross-checked with other radiometric data, calibration works in the case of AMS samples etc.). However, few samples satisfied these criteria. Therefore, detailed comparative works (horizon to horizon or site to site) are unreliable at this stage of research. The biased sample size also prohibits such comparisons. Chongokni has the largest number of handaxes $(\mathrm{N}=24)$, and so the mean and median values are adequate for evaluation, while Kawoli, Namkaeri, Shimgokni and others yielded only a single example (Table 1). The intercomparison will be performed at a later stage.

These three handaxe groups (regions) have different characteristic features. IHRB handaxes are likely the oldest. As explained, obtained data is not high standards in terms of chronological perspective. Nevertheless, the handaxes from many horizons are thought to be formed during the Middle Pleistocene. EC is likely the second oldest group. Wolso provided four OSL data related to handaxe-containing deposits $(89,000 \pm 4,000$, $79,000 \pm 5,000,81,000 \pm 10,000$ and $96,000 \pm 14,000$ BP) (YICP 2010). The oldest chronometric datum for Mansuri is $66,000 \pm 3,000 \mathrm{BP}$ (OSL) (Lee et al. 2010), while others are close to circa 30 kya.

The handaxes from the EC are distributed during a later period of time. Seokjangri has been studied meticulously and thoroughly. In spite of that, the age of Seokjangri cannot be confidently asserted. Paleolithic cultural episode of the site is still controversial, and the validity of pre-Late Paleolithic at the site is questioned (Seong 2015). Explanation of the details of its chronology is beyond the scope of this study.

\section{Trang 84}


Table 3. Selected Korean handaxes and flip test results. Note: Ref. N. is the original artifact serial number from the reference. The index of asymmetry (IA) was acquired in automatic mode (see Hardaker and Dunn 2005). The test was carried out in 'Auto Mode, Auto-Rotation' mode. If the handaxe images are correctly aligned, 'Auto Mode, No Rotation' mode is applied (Hardaker and Dunn 2005). Cortex Remaining $\%$ (CR \%) is provided to determine the magnitude of reduction. References: (Yi, Lee, and Kim 2004, Bae et al. 2011, RICP 1983, Kim et al. 2010, Yi, Yoo, and Kim 2006, KRIMH 2010, Yi, Yoo, and Kim 2011, Yi 2010, NRICP 1999, Lee 2009, Yi 2005, KRIMH 2012, Sohn 1993, 2009, JCPI 2006, Lee, Lee, and Kaoru 2011, Lee et al. 2010, 2009, IKP 2009, Kim et al. 2012, Yi 2006, Choi et al. 2003, YICP 2010, Ji et al. 2007).

\begin{tabular}{|l|l|l|l|l|l|l|}
\hline Site & Ref. N. & Length & Breadth & Thickness & IA & Mode \\
\hline Jangnamgyo & S0W1 20 & 147.0 & 110.0 & 78.0 & 2.86 & $\begin{array}{l}\text { No } \\
\text { Rotation }\end{array}$ \\
\hline Jangnamgyo & N0W1 99 & 158.0 & 88.0 & 82.0 & 2.90 & $\begin{array}{l}\text { No } \\
\text { Rotation }\end{array}$ \\
\hline Jangnamgyo & N1W1 10 & 123.0 & 95.0 & 67.0 & 7.65 & AR \\
\hline Jangnamgyo & N1W2 38 & 147.0 & 97.0 & 64.0 & 3.21 & $\begin{array}{l}\text { No } \\
\text { Rotation }\end{array}$ \\
\hline Jangnamgyo & N0W1 85 & 148.0 & 92.0 & 81.0 & 3.86 & AR \\
\hline Jangnamgyo & N1W3 78 & 116.0 & 79.0 & 81.0 & 4.83 & AR \\
\hline Jangnamgyo & S0W2 45 & 200.0 & 105.0 & 50.0 & 8.49 & AR \\
\hline Jangnamgyo & S0W4 17 & 164.0 & 102.0 & 66.0 & 2.76 & AR \\
\hline Jangnamgyo & Loc. 2 N10W19 1 & 166.0 & 105.0 & 74.0 & 8.42 & AR \\
\hline Chongokni & S1E18-12 & 184.0 & 95.0 & 64.0 & 6.17 & AR \\
\hline Chongokni & E1N9-III & 129.0 & 91.0 & 80.0 & 2.31 & AR \\
\hline Chongokni & E3N4 I -KYJ2-76 & 96.0 & 55.0 & 42.0 & 9.52 & AR \\
\hline Chongokni & E0S1 I -45 & 90.0 & 50.0 & 41.0 & 4.65 & AR \\
\hline Chongokni & E1S1 I -43 & 169.0 & 94.0 & 65.0 & 3.51 & AR \\
\hline Chongokni & E3S1- I -33 & 144.0 & 84.0 & 66.0 & 4.72 & AR \\
\hline Chongokni & E1-29 & 173.0 & 68.0 & 73.0 & 19.51 & AR \\
\hline Chongokni & W3-63 & 112.0 & 73.0 & 41.0 & 5.27 & AR \\
\hline Chongokni & E5S9-372 & 176.0 & 135.0 & 19.0 & 3.39 & AR \\
\hline Chongokni & TP I a & 124.0 & 91.0 & 54.0 & 4.41 & AR \\
\hline Chongokni & TP I b & 145.0 & 96.0 & 78.0 & 3.90 & AR \\
\hline Chongokni & E20N38-1 & 93.0 & 56.0 & 42.5 & 5.56 & AR \\
\hline Chongokni & E10S17-IV & 165.0 & 86.5 & 59.0 & 6.72 & $\begin{array}{l}\text { No } \\
\text { Rotation }\end{array}$ \\
\hline Chongokni & E14N8-IV & 136.0 & 99.0 & 66.0 & 2.29 & $\begin{array}{l}\text { No } \\
\text { Rotation }\end{array}$ \\
\hline Chongokni & W35N40- I & 129.5 & 80.5 & 55.5 & 6.23 & AR \\
\hline Chongokni & $\begin{array}{l}\text { KB-08-Chongok } \\
\text { 2.5-66 }\end{array}$ & 127.2 & 87.1 & 63.4 & 4.60 & $\begin{array}{l}\text { No } \\
\text { Rotation }\end{array}$ \\
\hline
\end{tabular}




\begin{tabular}{|c|c|c|c|c|c|c|}
\hline Chongokni & $\begin{array}{l}\text { KB-09-Chongok } \\
1.2-1-113\end{array}$ & 132.0 & 100.0 & 79.5 & 6.33 & AR \\
\hline Chongokni & $\begin{array}{l}\text { KB-09-Chongok } \\
1.2-1-104\end{array}$ & 105.0 & 85.5 & 46.0 & 4.15 & $\mathrm{AR}$ \\
\hline Chongokni & $\begin{array}{l}\text { KB-09-Chongok } \\
1.2-1-295\end{array}$ & 98.0 & 70.0 & 40.0 & 4.95 & $\mathrm{AR}$ \\
\hline Chongokni & NE13A-89 & 153.0 & 101.0 & 69.0 & 2.54 & AR \\
\hline Chongokni & SE11B-16 & 173.0 & 102.0 & 57.0 & 4.74 & AR \\
\hline Chongokni & NE11A-1 & 164.0 & 84.0 & 67.0 & 3.08 & $\mathrm{AR}$ \\
\hline Chongokni & NE07A-72 & 161.0 & 92.0 & 67.0 & 4.56 & $\mathrm{AR}$ \\
\hline Chongokni & NE06A-39 & 185.0 & 103.0 & 61.0 & 3.96 & $\mathrm{AR}$ \\
\hline Namkaeri & N/A & 118.60 & 89.30 & 89.30 & 4.99 & $\begin{array}{l}\text { No } \\
\text { Rotation }\end{array}$ \\
\hline Jangsanni & N/A & 232.5 & 121.5 & 86.0 & 4.19 & $\mathrm{AR}$ \\
\hline Kawoli & 53 & 136.0 & 94.0 & 73.0 & 5.34 & AR \\
\hline Kumpari & $92-234$ & 151.0 & 117.0 & 65.0 & 11.14 & AR \\
\hline Kumpari & $89-168$ & 142.0 & 92.0 & 41.0 & 7.13 & $\mathrm{AR}$ \\
\hline Kumpari & $91-264$ & 113.0 & 82.0 & 57.0 & 4.46 & $\mathrm{AR}$ \\
\hline Kumpari & $91-396$ & 218.0 & 114.0 & 64.0 & 6.85 & $\mathrm{AR}$ \\
\hline Kumpari & $91-450$ & 133.0 & 90.0 & 62.0 & 3.01 & $\mathrm{AR}$ \\
\hline Kumpari & $91-579$ & 207.0 & 124.0 & 59.0 & 2.43 & $\mathrm{AR}$ \\
\hline Kumpari & $92-350$ & 135.0 & 100.0 & 46.0 & 6.37 & AR \\
\hline Kumpari & $89-487$ & 143.0 & 88.0 & 46.0 & 6.35 & $\mathrm{AR}$ \\
\hline Kumpari & $90-20$ & 178.00 & 102.00 & 64.00 & 5.56 & $\mathrm{AR}$ \\
\hline Seokjangri & 1 & 110.8 & 74.8 & 38.8 & 4.34 & AR \\
\hline Seokjangri & 2 & 153.2 & 74.4 & 30.8 & 6.69 & AR \\
\hline Seokjangri & 513 & 91.0 & 69.6 & 37.0 & 7.69 & AR \\
\hline Seokjangri & 763 & 96.0 & 67.0 & 34.3 & 7.47 & AR \\
\hline Seokjangri & 3 & 163.7 & 102.8 & 46.8 & 2.73 & AR \\
\hline Seokjangri & $851-3010$ & 143.6 & 80.2 & 42.4 & 5.00 & AR \\
\hline Songduri & S-C6e+029-212 & 127.0 & 112.0 & 87.0 & 6.18 & $\mathrm{AR}$ \\
\hline Songduri & S-D10a1-308 & 154.0 & 102.0 & 60.0 & 4.49 & $\mathrm{AR}$ \\
\hline Songduri & S-C11d3-702 & 81.0 & 59.0 & 32.0 & 5.63 & $\mathrm{AR}$ \\
\hline Songduri & S-D17a3-10.3-738 & 153.0 & 101.0 & 50.0 & 3.76 & $\mathrm{AR}$ \\
\hline Songduri & S-D18d1-72-1242 & 158.0 & 106.0 & 71.0 & 7.21 & $\mathrm{AR}$ \\
\hline Nosanri & 738 & 124.1 & 96.6 & 72.6 & 2.14 & $\mathrm{AR}$ \\
\hline Nosanri & 813 & 113.6 & 86.9 & 72.6 & 3.29 & $\mathrm{AR}$ \\
\hline Nosanri & 306 & 108.1 & 75.5 & 50.2 & 5.97 & AR \\
\hline Mansuri & 981 & 122.4 & 97.1 & 62.4 & 5.86 & $\mathrm{AR}$ \\
\hline Mansuri & 235 & 83.0 & 40.0 & 46.0 & 5.07 & $\mathrm{AR}$ \\
\hline Mansuri & 447 & 107.0 & 78.0 & 57.0 & 2.71 & AR \\
\hline
\end{tabular}


TẠP CHÍ PHÁT TRIỂN KH\&CN, TẬP 19, Số X3-2016

\begin{tabular}{|l|l|l|l|l|l|l|}
\hline Mansuri & 702 & 218.0 & 82.0 & 87.0 & 3.58 & AR \\
\hline Mansuri & Mansu 14-4D-1 & 127.0 & 98.0 & 66.0 & 3.89 & AR \\
\hline Ssangjungri & 35 & 103.0 & 73.0 & 46.0 & 3.93 & AR \\
\hline Ssangjungri & 36 & 126.0 & 93.0 & 73.0 & 4.94 & AR \\
\hline Ssangjungri & 37 & 133.0 & 106 & 76 & 3.44 & AR \\
\hline Shimgokni & N/A & 175.0 & 106.0 & 40.0 & 3.68 & AR \\
\hline Nobong & 01b-166 & 154.0 & 87.0 & 33.0 & 3.53 & AR \\
\hline Wolso & WS-N9-7-4 & 162.4 & 98.4 & 36.0 & 9.31 & AR \\
\hline Wolso & WS-O8-7-15 & 164.7 & 110.0 & 56.3 & 7.89 & AR \\
\hline Wolso & WS-J8-7-1 & 203.0 & 106.1 & 45.4 & 4.73 & AR \\
\hline Wolso & WS-K8-7-1 & 161.6 & 112.4 & 33.8 & 4.63 & AR \\
\hline Wolso & WS-E4-6-1 & 148.8 & 86.9 & 65.8 & 8.48 & AR \\
\hline Wolso & WS-N5-6-5 & 114.7 & 70.1 & 30.5 & 5.60 & AR \\
\hline Wolso & WS-C5-4-1 & 101.8 & 91.8 & 71.8 & 6.08 & AR \\
\hline Wolso & WS-E3-4-1 & 189.5 & 102.8 & 65.7 & 4.94 & AR \\
\hline Wolso & WS-F3-4-1 & 139.2 & 93.4 & 60.1 & 4.61 & AR \\
\hline Pyeongneungdong & E8-<1>-18 & 138.0 & 91.0 & 58.0 & 5.46 & AR \\
\hline Pyeongneungdong & E8-<2>-3 & 166.0 & 95.0 & 53.0 & 7.24 & AR \\
\hline Pyeongneungdong & E8-<2>-5 & 189.0 & 96.0 & 57.0 & 3.20 & AR \\
\hline
\end{tabular}

Some sites in the region show much younger depositional features. Songduri has been excavated and handaxes discovered in stratified deposits. Unfortunately, the radiometric results cannot be obtained. Nosanri provides two different OSL results: $48,000 \pm 4,000$ and 49,000 $\pm 4,000$ BP (Lee, Lee, and Kaoru 2011). Ssangjungri is the most recently excavated site in the region. As explained, the calibrated age is around 30 kya. Because of the complicated artifact chronology, it is difficult and premature to state that all the sites in the region belong to younger deposits. Nevertheless, a relatively younger time span tends to be postulated.

In the context of the African and European Acheulean handaxe industries, handaxes with other core tools such as cleavers are regarded as Mode 2 (Lycett and von Cramon-Taubadel 2008) and persisted from 1.7 to 0.25 Mya (McNabb, Binyon, and Hazelwood 2004). However, their occurrence extends to within 30 kya in the Korean context (Lee 2013b). Since Mode 2 belongs to the Lower Paleolithic period, the evolution of the lithic industry was in a static condition. The consistency of simply made tools through time might be interpreted as odd in the perspective of the normal lithic evolutionary scheme. However, Korean handaxes sometimes appeared in the Late Paleolithic period.

Early versions were simple core and flake tools, while later versions were refined tools, such as blades. Therefore, the later handaxes were of more refined, symmetrical forms than the earlier samples. The general idea is that refined forms of handaxes are normally symmetrical. In Europe, the general consensus is 'smaller, thinner, more regular, and symmetrical forms appear in the later part of the Acheulean' (Stout et al. 2014, 577).

Table 3 shows the index of asymmetry (IA) values. All cases $(\mathrm{N}=81)$ were tested using the flip test. The mean value of the 81 cases is 5.25. According to the class category (Classes 1 to 6) suggested by Hardaker and Dunn (Hardaker and Dunn 2005), they were Class 5, which indicates a crude symmetrical form. This might be due to poor 
raw material quality, the lack of an authentic functional purpose or something else. In fact, many handaxes in Korea are of coarse-grained raw materials, such as quartz and quartzite (Seong 2004). These are widely distributed throughout the peninsula. They have a coarse-grained texture, which can result in generation of crude facture patterns.

Additionally, the degree of symmetry may differ over time. For example, early handaxes might have poor symmetry in comparison with those from a later period. The proposed implication is whether symmetry is homogeneous (pervasive, no significant alternation) regardless of time or symmetry is increased (significant alternation) with the advance of time.

To determine whether the degree of symmetry is homogeneous, not only the chronological time span and rock quality but also migration of the tool makers interactive contacts, geographical variations, blank shapes etc must be considered. However, it is difficult to include all possible factors. Some of them can be reached to a certain conclusion and others are not.

For example, rock quality is a crucial determinant of symmetry variation. As explained, quartzite or rocks of a similar quality are frequently used. Such rocks might not ideal for such refined artifacts. Demonstrating the deliberate procurement of resources of ideal and non-ideal quality for tool making and comparison of their symmetry are required. Some quartzite materials have been reported to show a fine rather than a coarse grain structure (Yoo 2003). However, quartzite does not have a predictable conchoidal fracture, so that such rocks are not cryptocrystalline siliceous rocks. To produce a more refined and more symmetrical handaxe, alternative rocks should be used. However, such non-quartzite handaxes are rare. Unfortunately, most of the handaxes suggested in the paper are of quartzite. No comparison can be made due to the small number of non-quartzite handaxes. Therefore, such determination is beyond the scope of this paper.

It is seemingly that determining symmetry of the Korean Paleolithic handaxes classified according to chronological data is more practical way to study. Most of the absolute chronological data come from the available literature, which are derived from excavations. Moreover, the samples are chronologically varied, which facilitates comparison. However, some drawbacks must also be considered, as the published radiometric data are not always promising. The processes involved in obtaining, measuring and calculating radiometric data are subject to error and the credibility of the dates is questionable. Indeed, accommodating all possibilities in the paper is impossible. For this reason, a roughly bounded regional comparison of the symmetrical tendency of handaxes was performed.

Table 4. Mean index of asymmetry values of three regions

\begin{tabular}{|l|l|l|}
\hline Region & $\mathrm{N}$ & Mean IA \\
\hline $\begin{array}{l}\text { Imjin/Hantan River Basins } \\
\text { (IHRB) }\end{array}$ & 45 & 5.33 \\
\hline Geum River Basin (GRB) & 22 & 4.82 \\
\hline East Coast (EC) & 14 & 5.67 \\
\hline
\end{tabular}

The results are shown in Table 4 . The number of handaxes in the Imjin/Hantan River Basins (IHRB), Geum River Basin (GRB) and East Coast (EC) was 45, 22 and 14, and they exhibited symmetry values of 5.33, 4.82 and 5.67, respectively (lower values indicate better symmetry). The hypothesis is that later samples will have better symmetry due to the process of cultural evolution. The (proposed) youngest group is GRB, the degree of symmetry of later examples of which is improved compared to the earlier samples. In other words, if the hypothesis is correct, the mean values decrease over time.

The GRB value is smaller than that of the other locations. However, the difference in symmetry between the late (samples from the GRB) and early phases (samples from the IHRB and EC) is only

\section{Trang 88}


0.51-0.85. Whether these differences are not significantly meaningful relative to the complete range of symmetry from 1.00 to 6.00 should be determined (Table 2). The values are distributed in Class 4 or 5. Class 1 indicates a superb example and Class 6 shows a poorly made. Thus it is not possible to ascertain that handaxes from the GRB exhibit better symmetry.

Table 5. Standard deviations (SDs) of the index of asymmetry of three regions. Note: singlehandaxe sites are not included.

\begin{tabular}{|l|l|l|}
\hline \multirow{4}{*}{ Region } & Site & $\begin{array}{l}\text { Mean } \\
\text { SD }\end{array}$ \\
\hline \multirow{4}{*}{ IHRB } & Jangnamgyo & 2.49 \\
\cline { 2 - 3 } & Chongokni & 3.43 \\
\cline { 2 - 3 } & Kumpari & 2.57 \\
\hline \multirow{5}{*}{ GRB } & Seokjangri & 2.00 \\
\cline { 2 - 3 } & Songduri & 1.36 \\
\cline { 2 - 3 } & Nosanri & 1.97 \\
\cline { 2 - 3 } & Mansuri & 1.25 \\
\cline { 2 - 3 } & Ssangjungri & 0.77 \\
\hline \multirow{2}{*}{ EC } & Wolso & 1.83 \\
\cline { 2 - 3 } & Pyeongneungdong & 2.03 \\
\hline
\end{tabular}

The earlier handaxes from the IHRB and EC do not differ markedly over time. On the contrary, the opposite is true; the value of EC (5.67) is greater than that of IHRB (5.33). The EC sites are regarded as younger, but the handaxes lack refined symmetries. Thus the given data do not present a clear demarcation through time. These results emphasize that symmetry differs between the samples from GRB versus those from the IHRB and EC. Therefore, the variations in symmetry between these groups are not significant and no consistent tendency is observed.

Furthermore, the symmetry value of standard deviation (SD) is considered. The SD demonstrates the closeness of the samples to the mean values. Lower SD values indicate that the samples are the close to the mean value; otherwise, they are widely dispersed. In terms of cultural complexity, the Late Paleolithic shows a high standard of lithic manufacture. With regard to the general features of the Late Paleolithic, the tools are standardized and very similar. In such a case, the symmetrical index would be almost equal and show lower values. Some sites show a single handaxe, and thus were excluded from the calculation. Table 5 shows SD values of workable sites.

The SD values from GRB are 2.00 (Seokjangri), 1.36 (Songduri), 1.97 (Nosanri), 1.25 (Mansuri), and 0.77 (Ssangjungri). These values are lower than those of IHRB sites (Jangnamgyo, Chongokni and Kumpari) which are 2.49 or greater, suggesting that handaxes from GRB exhibit that the values are close to each other or greater, suggesting that handaxes from GRB exhibit that the values are close to each other, suggestive of standardized lithic manufacture.

However, it is doubt. EC also exhibits such a standardization tendency over time. The values from EC are 1.83 (Wolso) and 2.03 (Pyeongneungdong), which are similar to those of GRB. Therefore, it is difficult to conclude that the whole standardization tendency is progressed. A pervasive symmetrical tendency between GRB and EC has been noted, so that a strong progressive feature cannot be claimed.

\section{Conclusion}

Symmetry might be defined as an indicator of balance and regularity and this attribute is interpreted to be mediated by a social-learning mechanism. A preference symmetrical pattern on handaxes might be thought as the promise for increasing our understanding of the behavior of Paleolithic humans.

Like other attributes, the symmetry could be thought to be related to the social information transmission. As well as the complexity of lithic technology and variation of morphology are crucial for understanding handaxes and the behavior of toolmakers. However, it needs to reconsider whether the symmetry strongly correlates to the social learning or not. 
The author does not disregard the importance of whole sets of cultural phenomena. Most culturally transmitted human behavior can be changed. However, the attribute of symmetry should not be considered in the same way. The tendency towards symmetrical behavior is difficult to change.

The present author does not wish to suggest that the whole techno-complex is static. As matter of fact, a pattern of evolved technologies, typological variation and refined raw material consumption over time may be found. However, the key point is that the symmetry of handaxes seems to be a particularly independent of a given space and time. Therefore, intentionally made symmetrical forms might be something beyond culturally specific entities.

\section{Phát hiện sự đồng dạng của rìu tay trong một sưu tập ở Hàn Quốc}

\section{- Hyeong Woo Lee}

Đại học Quốc gia Chonbuk, Hàn Quốc

Cách đánh giá mang tính hệ thống rất quan trọng trong việc tìm hiểu hành vi của con người. Hiện vật rìu tay thời đại Đá cũ là đối tượng quan trọng để phân tích định lượng. Để tránh cách đánh giá theo quan điểm cá nhân và độc đoán, cần phải có một phương pháp đánh giá khách quan hơn. Gần đây một số thiết bị khả thi có thể đo lường tinh vi được áp dụng trong nghiên cứu. Một trong số đó là "thí nghiệm tác động" (Flip Test) lên hiện vật được sử dụng để định lượng các đặc điểm khác nhau của hiện vật rìa tay thuộc thời đại Đá cũ tìm thấy ở Hàn Quốc...

Thông thường, hiện vật rìu đá ở Hàn Quốc trong các bộ sưu tập là những công cu được chế tác hoàn chỉnh và các mảnh tước được ghè đẽo. Không giống như loại rìu Acheulean điển hình, rìu đá Hàn Quốc không được thể hiện theo xu hướng tiêu chuẩn hóa. Các câu hỏi chính ở đây là liệu có các kiểu mẫu đa dạng được tiếp nối trong một hướng phát triển đơn lẽ hay không (mức độ gia tăng mang tính hệ thống với niên đại di chỉ sẽ chỉ ra được sự phát triển của văn hóa và kỹ nghệ chế tác). Tuy nhiên, kết quả nghiên cứu đã không thể chứng minh đầy đủ mối quan hệ có ý nghĩa. Nói cách khác, tính đồng nhất trong nghiên cứu đối xứng về rìu đá cần phải tiếp tục khảo sát.

Keywords: Hàn Quốc, rìu tay, tính đối xứng, thí nghiệm tác động

\section{Trang 90}




\section{References}

[1]. Ambrose, Stanley H. 2001. "Paleolithic technology and human evolution." Science 291 (5509):1748-1753. doi: 10.1126/science.1059487.

[2]. Bae, K. D. 2003. "Review of chronological researches of the Chongokni site." Geological Formation of the Chongokni Paleolithic Site and Paleolithic Archaeology in East Asia, Yeoncheon.

[3]. Bae, K. D., C. M. Lee, S. M. Jeong, K. R. Kim, and K. H. Sun. 2011. The Jangnamgyo Paleolithic Site, Yeoncheon, Korea. Ansan: Institute of Cultural Properties, Hanyang University.

[4]. Bae, K. D., and Koh. J. W. 1993. Report of Excavation of the Chongokni Paleolithic Site for 1992. Seoul: Department of Cultural Anthropology, Hanyang University.

[5]. Bae, Kidong. 1988. "The significance of the Chongokni stone industry in the tradition of Paleolithic culture in East Asia." Ph.D. Dissertation, Department of Anthropology, University of California, Berkeley.

[6]. Bae, Kidong. 2010. "Peopling in the Korean Peninsula." In Asian Paleoanthropology: from Africa to China and beyond, edited by Christopher J. Norton and David R. Braun, 181-190. London, New York: Springer Netherlands.

[7]. Britannica, The Editors of Encyclopædia. 2016. "Encyclopædia Britannica." Encyclopædia Britannica, Inc.

[8]. Choi, B. , S. An, H. Ryu, and J. Moon. 2003. Nobong Paleolithic site, Chuncheon. Chuncheon: The Institute of Archaeology, Gangwon University.

[9]. Choi, S. Y. 2010. "A Study on the Paleolithic Culture in Gangwon Province, Korea." 박사, Kangwon University, Kangwon University.

[10]. Corvinus, Gudrun. 2004. "Homo erectus in East and Southeast Asia, and the questions of the age of the species and its association with stone artifacts, with special attention to handaxe-like tools." Quaternary International 117 (1):141-151.

[11]. Gibbon, Ryan J., Darryl E. Granger, Kathleen Kuman, and Timothy C. Partridge. 2009. "Early Acheulean technology in the Rietputs Formation, South Africa, dated with cosmogenic nuclides." Journal of Human Evolution 56 (2):152-160.

[12]. Hardaker, Terry, and Stephen Dunn. 2005. "The Flip Test-a new statistical measure for quantifying symmetry in stone tools." Antiquity 79 (306).

[13]. ICPH. 2009. Report of Excavation of The Chongokni Paleolithic Site, Section 5-2. Ansan: Institute of Cultural Properties, Hanyang University.

[14]. IKP. 2009. Report on the Excavation of Mansu-ri Paleolithic Site (Loc. 14). Cheongju: The Institute of Korean Prehistory.

[15]. JCPI. 2006. Jinchon Songduri Paleolithic site I. Cheongju: Jungwon Cultural Properties Institute.

[16]. Ji, H. B., H. Y. Lee, C. H. Lee, Y. S. Choi, and N. R. Lee. 2007. Pyoungreung-dong Palaeolithic Site, Chuncheon. Chuncheon: Gangwon Research Institute of Cultural Properties.

[17]. Kim, Dongwan. 2009. "A Morphological Analysis of the Large Cutting Tools from the Imjin-Hantan River Area: Focusing on the Analysis of Asymmetry." master degree, The Graduate School Seoul National University Seoul National University.

[18]. Kim, J. C., G. Duller, H. Roberts, A. Wintle, Y. I. Lee, and S .B. Yi. 2010. "Re-evaluation of the chronology of the palaeolithic site at Jeongokri, Korea, using OSL and TT-OSL signals from quartz." Quaternary Geochronology 5 (2-3):365-370. 
[19]. Kim, M. R., J. Kim, H. S. An, and E. Y. Song. 2012. Ssangjung-ri Paleolithic site, Iksan. Jeonju: Jeolla Research Institute of Cultural Heritage.

[20]. Kim, Y., and Y. Chung. 1978. "Preliminary Report of Acheulean Handaxe at Chongok-ri." Jindan Hakbo 46/47:5-56.

[21]. Klein, Richard G. 2009. The human career: human biological and cultural origins (2nd). Chicago and London: University of Chicago Press.

[22]. KRIMH. 2010. Jeongok-ri Paleolithic site Yeoncheon, Gyeonggi Province, Korea. Seoul: Korea Research Institute of Military Heritage.

[23]. KRIMH. 2012. Excavation report of Gawol-ri, Jeokseong-myeon, Paju-si, Gyeongi-do, Korea. Seoul: Korea Research Institute of Military Heritage.

[24]. Lee, C. M. 2009. "A study of flake from the Kumpari Paleolithic site, Paju." Master Degree, Department of Cultural Anthropology, Hanyang University.

[25]. Lee, Hyeong Woo. 2006. "A metrical analysis of Palaeolithic handaxes in Korea: identification for shape consistency." Korea Journal 46:188-211.

[26]. Lee, Hyeong Woo. 2011. "Implication of the Bilateral Symmetry on Handaxes in Korea." Social Science Studies 35 (2):277-316.

[27]. Lee, Hyeong Woo. 2013a. "Current observations of the early Late Paleolithic in Korea." Quaternary International 316:45-58.

[28]. Lee, Hyeong Woo. 2013b. "The Persistence of Mode 1 Technology in the Korean Late Paleolithic." PLOS ONE 8 (5):e64999.

[29]. Lee, Y. J., S. W. Lee, J. H. An, M. K. Kang, and Y. Kaoru. 2009. Report on the Excavation of Mansu-ri Paleolithic Site (Loc. 12), Cheongwon. Cheongju: The Institute of Korean Prehistory.

[30]. Lee, Y. J., S. W. Lee, J. H. An, M. K. Kang, and Y. Kaoru. 2010. Report on the Excavation of Mansu-ri Paleolithic Site (Loc. 1, 2, 3), Cheongwon. Cheongju: The Institute of Korean Prehistory.

[31]. Lee, Y. J., S. W. Lee, and Y. Kaoru. 2011. Report on the excavation Nosan-ri Paleolithic site (Localities 3, 4, 5), Cheongwon. Cheongju: The Institute of Korean Prehistory.

[32]. Lycett, Stephen J., and Noreen von CramonTaubadel. 2008. "Acheulean variability and hominin dispersals: a model-bound approach." Journal of Archaeological Science 35 (3):553562. doi: 10.1016/j.jas.2007.05.003.

[33]. McNabb, John, Francesca Binyon, and Lee Hazelwood. 2004. "The Large Cutting Tools from the South African Acheulean and the Question of Social Traditions." Current Anthropology 45 (5):653-677. doi: $10.1086 / 423973$.

[34]. Mitchell, J. 1996. "Studying biface butchery at Boxgrove: roe deer butchery with replica handaxes." Lithics (the Journal of the Lithic Studies Society) (16):64-69.

[35]. Movius, Hallam. 1948. "The Lower Palaeolithic cultures of Southern and Eastern Asia." Transactions of the American Philosophical Society 38 (4):329-420.

[36]. Norton, Christopher J., and Kidong Bae. 2009. "Erratum to "The Movius Line sensu lato (Norton et al., 2006) further assessed and defined" JH Evol. 55 (2008) 1148-1150." Journal of Human Evolution 57 (3):331-334.

[37]. Norton, Christopher J., Kidong Bae, John W. K. Harris, and Hanyong Lee. 2006. "Middle Pleistocene handaxes from the Korean peninsula." Journal of Human Evolution 51 (5):527-536.

[38]. NRICH. 2013. Dictionary of Korean Archaeology: the Paleolithic Age. Daejeon: National Research Institute of Cultural Heritage.

[39]. NRICP. 1999. Kumpari Paleolithic site report of excavations in 1989 1992. Seoul: National 
Research Institute of Cultural Properties, Korea.

[40]. Petraglia, Michael D., and Ceri Shipton. 2008. "Large cutting tool variation west and east of the Movius Line." Journal of Human Evolution 55 (6):962-966.

[41]. RICP. 1983. Chongokni. Seoul: Research Institute of Cultural Properties.

[42]. Roe, Derek. 1968. "British Lower and Middle Palaeolithic Handaxe Groups." Proceedings of the Prehistoric Society 34:1-82.

[43]. Roe, Derek. 1981. The Lower and Middle Palaeolithic Periods in Britain. London, Boston and Henley: Routledge \& Kegan Paul.

[44]. Roebroeks, W., N.J. Conard, T. van Kolfschoten, RW Dennell, R.C. Dunnell, C. Gamble, P. Graves, K. Jacobs, M. Otte, and D. Roe. 1992. "Dense Forests, Cold Steppes, and the Palaeolithic Settlement of Northern Europe [and Comments and Replies]." Current Anthropology 33 (5):551-586.

[45]. Saragusti, Idit, and Naama Goren-Inbar. 2001. "The biface assemblage from Gesher Benot Ya'aqov, Israel: illuminating patterns in "Out of Africa" dispersal." Quaternary International 75 (1):85-89.

[46]. Saragusti, Idit, Ilan Sharon, Omer Katzenelson, and David Avnir. 1998. "Quantitative analysis of the symmetry of artefacts: Lower Paleolithic handaxes." Journal of Archaeological Science 25 (8):817825.

[47]. Schick, K. 1994. "The Movius line reconsidered." In Integrative Paths to the Past, edited by R. S. Corruccini and R . L. Ciochon, 569-596. NJ: Prentice Hall.

[48]. Seong, Chuntaek. 2004. "Quartzite and vein quartz as lithic raw materials reconsidered: a view from the Korean Paleolithic." Asian Perspectives 43 (1):73-91.

[49]. Seong, Chuntaek. 2006. "A comparative and evolutionary approach to the Korean
Paleolithic assemblages." Journal of Korean Ancient Historical Society 51:5-42.

[50]. Seong, Chuntaek. 2015. "A history of Paleolithic archaeology in Korea: a preliminary assessment " History of Korean Archaeology I, Jeonju City, Korea.

[51]. Sohn, P. K. 1967. "Stratified Palaeolithic Cultures Newly Excavated in Korea." The Journal of the Korean Historical Association 35-36:1-25.

[52]. Sohn, P. K. 1972. "The Korean Culture in the Old Stone Age." The Paekche Yonku 3:55-72.

[53]. Sohn, P. K. 1993. Seokjangri Prehistoric site. Seoul: Dong-A Publication.

[54]. Sohn, P. K. 2002. "From history to prehistory." In Paleolithic Culture in Korea, edited by Y. J. Park, 9-21. Seoul: Yonsei University Press.

[55]. Sohn, P. K. 2009. The Seokchangni site and the Palaeolithic culture of Korea. Seoul: Hakyoun Press.

[56]. Stout, Dietrich, Jan Apel, Julia Commander, and Mark Roberts. 2014. "Late Acheulean technology and cognition at Boxgrove, UK." Journal of Archaeological Science 41:576590.

[57]. Wynn, Thomas, and Forrest Tierson. 1990. "Regional Comparison of the Shapes of Later Acheulean Handaxes." American Anthropologist $92 \quad$ (1):73-84. doi: 10.1525/aa.1990.92.1.02a00050.

[58]. Yi, Seonbok. 1996. "Chronostratigraphy of Palaeolithic occurrences in the Imjin Basin." Journal of the Korean Archaeological Society 34:135-160.

[59]. Yi, Seonbok. 2005. "New data on the formation of the basalt plain in the Imjin River basin." Journal of the Geomorphological Association of Korea 12:29-48.

[60]. Yi, Seonbok. 2006. Excavation report at Shimgok-ni. Seoul: Seoul National University Museum. 
[61]. Yi, Seonbok. 2010. "Radiocarbon Age of the Basalt Plain in the Imjin Basin: Archaeological Implications." Journal of the Korean Palaeolithic Society 22:3-20.

[62]. Yi, Seonbok, Y. I. Lee, and J. W. Kim. 2004. "The Jangsan-ri Terrace and Lava Deposit in the Upstream Areas of the Imjin River." Journal of the Korean geomorphological association 11:77-90.

[63]. Yi, Seonbok, Yongwook Yoo, and Dongwan Kim. 2006. Excavation Report at Jeongok ACF site and its vicinity. Seoul: Seoul National University Museum.
[64]. Yi, Seonbok, Yongwook Yoo, and Dongwan Kim. 2011. Excavation in the road construction site of the Jung 2-5 line in Jeongok-ri (Chongokni). Seoul: Seoul National University Museum.

[65]. YICP. 2010. Report on the excavation of Wolso Site, Mukhojin-dong, Donghae. Chuncheon: Yemaek Institute of Cultural Properties.

[66]. Yoo, Yongwook. 2003. "Rethinking of Quartz as Raw Material: Examples from Pyongchangni Site." Geological Formation of the Chongokni Paleolithic Site and Paleolithic Archaeology in East Asia, Yeoncheon. 